\title{
Evaluation of Antifungal Activity and Mechanism of Action of Citral against Candida albicans
}

\section{Maria Clerya Alvino Leite, ${ }^{1,2}$ André Parente de Brito Bezerra, ${ }^{2}$ Janiere Pereira de Sousa, Felipe Queiroga Sarmento Guerra, ${ }^{2}$ and Edeltrudes de Oliveira Lima ${ }^{2}$}

\author{
${ }^{1}$ Federal Institute of Education, Science, and Technology of Paraíba (IFPB), 58780-000 Itaporanga, PB, Brazil \\ ${ }^{2}$ Mycology Laboratory, Department of Pharmaceutical Sciences, Federal University of Paraíba, 58051-970 João Pessoa, PB, Brazil
}

Correspondence should be addressed to Maria Clerya Alvino Leite; cleryaalvino@hotmail.com

Received 23 May 2014; Revised 16 July 2014; Accepted 5 August 2014; Published 28 August 2014

Academic Editor: Didier Stien

Copyright (C) 2014 Maria Clerya Alvino Leite et al. This is an open access article distributed under the Creative Commons Attribution License, which permits unrestricted use, distribution, and reproduction in any medium, provided the original work is properly cited.

\begin{abstract}
Candida albicans is a yeast that commensally inhabits the human body and can cause opportunistic or pathogenic infections. Objective. To investigate the antifungal activity of citral against C. albicans. Methodology. The minimum inhibitory concentration (MIC) and the minimum fungicidal concentration (MFC) were determined by the broth microdilution techniques. We also investigated possible citral action on cell walls $(0.8 \mathrm{M}$ sorbitol), cell membranes (citral to ergosterol binding), the time-kill curve, and biological activity on the yeast's morphology. Results. The MIC and MFC of citral were, respectively, $64 \mu \mathrm{g} / \mathrm{mL}$ and $256 \mu \mathrm{g} / \mathrm{mL}$. Involvement with the cell wall and ergosterol binding were excluded as possible mechanisms of action. In the morphological interference assay, it was observed that the product inhibited pseudohyphae and chlamydoconidia formation. The MIC and the MFC of citral required only 4 hours of exposure to effectively kill $99.9 \%$ of the inoculum. Conclusion. Citral showed in vitro antifungal potential against strains of C. albicans. Citral's mechanism of action does not involve the cell wall or ergosterol, and further study is needed to completely describe its effects before being used in the future as a component of new antifungals.
\end{abstract}

\section{Introduction}

The prevalence of Candida albicans infections is increasing at an alarming rate, and this is especially true for immunocompromised individuals, such as AIDS patients, transplant patients, and neonates $[1,2]$. C. albicans is an opportunist pathogen that lives commensally within the human body; it is the leading cause of human fungal infections. C. albicans infection usually develops as a consequence of host immune response alterations [3].

The increased incidence of Candida infections can be attributed to a variety of factors, either exogenous or (especially) endogenous. Over 100 species of Candida are known; C. albicans is the main representative. The frequency of distribution for Candida spp. varies in accordance with geographical location. Among the Candida species, it is $C$. albicans that is involved in bloodstream infections for $44 \%$ of Latin American and 62\% of European cases [4].
Conventional fungal infection treatments are unsatisfactory. Therefore, it has become essential to develop new drugs and alternative therapies (including natural products) for the treatment of $C$. albicans infections. Plants and their derivatives are known to be important in pharmacological research due to their great potential as a source for a variety of biologically active ingredients used in drug development. Amongst these products we find the terpenes, a class of natural substances of vegetable origin formed by combining five carbons called isoprene $\left(\mathrm{C}_{5} \mathrm{H}_{8}\right)$. Terpenes can be classified according to their number of isoprene units: monoterpenes $\left(\mathrm{C}_{10}\right)$, the most representative molecules, and sesquiterpenes $\left(\mathrm{C}_{15}\right)$, but there are also hemiterpenes $\left(\mathrm{C}_{5}\right)$, diterpenes $\left(\mathrm{C}_{20}\right)$, triterpenes $\left(\mathrm{C}_{30}\right)$, and tetraterpenes $\left(\mathrm{C}_{40}\right)$ [5].

Citral (3,7-dimethyl-2-6-octadienal) is the name given to a mixture of two geometric isomers: geranial (trans-citral, citral A) and neral (cis-citral, citral B), which are acyclic $\alpha$, $\beta$-unsaturated monoterpene aldehydes that occur naturally 
in many essential citrus fruit oils and in other herbs or spices [6-10]. The citral aroma is stronger and sweeter than that of lemon. Geranial has a strong lemon odor while neral has a sweeter, yet less intense lemon odor. Due to its characteristic lemon aroma, citral has become a flavoring substance of great importance, a heavily used raw material for the pharmaceutical, food, perfume, and cosmetics industries $[11,12]$.

The antifungal activity exerted by citral against molds and yeasts has already been demonstrated in varied conditions $[10,13-20]$. Recently, it was demonstrated that citral has the ability to destroy the integrity of the cell membrane, releasing the cellular components of Geotrichum citri-aurantii [21] and dramatically inhibiting the mycelial growth of Penicillium italicum through a mechanism of cell membrane damage, compromising its integrity and permeability [22]. Da silva et al. [23] have demonstrated that citral exhibits significant in vitro activity against C. glabrata, C. krusei, C. parapsilosis, and $C$. tropicalis, and especially against species of $C$. albicans. Zore et al. [24] demonstrated the anti-Candida activity of six terpenoids; all showed excellent activity against $C$. albicans isolates, being the most effective linalool and citral.

Given the above, the aim of this study was to determine the minimum inhibitory concentration (MIC) and the minimum fungicidal concentration (MFC) and to investigate the action mechanism of citral against $C$. albicans in its growth kinetics, micromorphology, cell wall formation, and ergosterol interactions.

\section{Materials and Methods}

2.1. Phytoconstituent, Antifungal Standard, and Substances. The following substances used in this work were obtained commercially: citral (purity 95\%), amphotericin B, ergosterol, and sorbitol (all from Sigma-Aldrich, São Paulo, SP, Brazil). Furthermore, dimethylsulfoxide (DMSO) and Tween-80 were, respectively, purchased from Labsynth Products for Laboratories Ltd. (Diadema, SP, Brazil) and Vetec Fine Chemicals Ltd. (Duque de Caxias, RJ, Brazil).

2.2. Culture Media. To test the biological activity of the products, Sabouraud dextrose broth (SDB) and Sabouraud dextrose agar (SDA) were purchased from Difco Laboratories (Detroit, MI, USA) and agar-cornmeal from HiMédia Laboratories (Mumbai, India), and RPMI-1640-L-glutamine (without sodium bicarbonate) (Sigma-Aldrich, São Paulo, SP, Brazil) culture media were used. They were prepared and used according to the manufacturers' instructions.

2.3. Fungal Strains. The assays were performed with 10 strains of C. albicans: LM-14, LM-17, LM-70, and LM-520 (isolated from blood cultures), LM-11, LM-15, LM-94, and LM-410 (lung secretion), and two standard C. albicans strains: ATCC 76485 and ICB-12. All strains belong to the collection of the Mycology Laboratory, Department of Pharmaceutical Sciences, Federal University of Paraíba (LM, DCF, UFPB). These strains were maintained in SDA at $35^{\circ} \mathrm{C}$ and $4^{\circ} \mathrm{C}$ until used in tests.
2.4. Inoculum Preparation. The suspensions were prepared from recent $C$. albicans cultures, plated on SDA, and incubated at $35^{\circ} \mathrm{C}$ for $24-48 \mathrm{~h}$. After incubation, we transferred roughly 4-5 yeast colonies (with a sterile loop) to test tubes containing $5 \mathrm{~mL}$ of saline solution $0.9 \%$ (Farmax-Distributor Ltd., Amaral, Divinópolis, MG, Brazil). The resulting suspensions were stirred for 15 seconds with the aid of a Vortex apparatus (Fanem Ltd., Guarulhos, SP, Brazil).

The turbidity of the final inoculum was standardized using a barium sulfate suspension (tube 0.5 on the McFarland scale). The final concentration obtained was about 1$5 \times 10^{6}$ colony forming units per milliliter $(\mathrm{CFU} / \mathrm{mL})$. The final concentration confirmation was done by counting the microorganisms in a Neubauer chamber [25-27].

2.5. Determination of Minimum Inhibitory Concentration (MIC) and Minimum Fungicidal Concentration (MFC). The determination of the products' MIC on the ten strains used in the biological assays was determined by the broth microdilution method [25-27]. One hundred milliliters $(100 \mu \mathrm{L})$ of liquid medium RPMI-1640 was transferred into the wells of a 96-well microdilution plate with a "U" shaped bottom (Alamar, Diadema, SP, Brazil). Then, $100 \mu \mathrm{L}$ of citral emulsion was inoculated in the first horizontal row of the plate wells. Doubled serial dilutions, where a $100 \mu \mathrm{L}$ aliquot removed from the most concentrated well went to the next well, yielded concentrations of $1024-1 \mu \mathrm{g} / \mathrm{mL}$. Finally, $10 \mu \mathrm{L}$ of C. albicans inoculum suspension was added to each well of the plate, where each column represented a yeast strain. In parallel, controls were made for yeast viability and for susceptibility with the standard antifungal amphotericin $\mathrm{B}$. The plates were incubated at $35^{\circ} \mathrm{C}$ for $24-48 \mathrm{~h}$. After the appropriate incubation time, the presence (or absence) of growth was observed visually. The formation of cell clusters or "buttons" in the plate wells was considered. The MIC was defined as the lowest citral concentration that produced visible inhibition of yeast growth.

The antimicrobial activity of the products was interpreted (considered active or not), according to the criteria proposed by Morales et al. [28]: strong/good activity (MIC: $<100 \mu \mathrm{g} / \mathrm{mL}$ ); moderate activity (MIC: $100-500 \mu \mathrm{g} / \mathrm{mL}$ ); weak activity (MIC: $500-1000 \mu \mathrm{g} / \mathrm{mL}$ ); and inactive product/no antimicrobial effect (MIC: $>1000 \mu \mathrm{g} / \mathrm{mL}$ ).

To determine the MFC, we subcultured $1 \mu \mathrm{L}$ aliquots of MIC, MIC $\times 2$, and MIC $\times 4$ of the citral products, amphotericin $\mathrm{B}$, and the control yeast growth onto Petri dishes containing SDA. After 24-48 hours of incubation at $35^{\circ} \mathrm{C}$, a reading was made to evaluate the $\mathrm{MFC}$, as based on the growth of the controls. The MFC was defined as the lowest product concentration that inhibited growth of the yeast or permitted less than three CFUs to occur, resulting thus in $99.9 \%$ fungicidal activity $[29,30]$.

Biological activity assays were performed in duplicate, and the results were expressed as the arithmetic mean of the MIC and MFC.

2.6. Time-Kill Curve. The study of citral and amphotericin $B$ interference on the death curve times for C. albicans was 
conducted with methodology described by Klepser et al. [31], with some modifications, using the method of counting viable cells. To determine the kinetics of fungal death, two strains were selected: a standard strain ATCC 76485 and a clinical strain LM-70, in accordance with the MIC and MFC results. In this test, the behavior of selected yeast strains was observed for $24 \mathrm{~h}$.

A series of sterile test tubes was prepared and we added $4.5 \mathrm{~mL}$ of RPMI 1640 medium containing various product concentrations: $\mathrm{MIC} / 2, \mathrm{MIC}$, and MIC $\times 2$. We then added $0.5 \mathrm{~mL}$ of the yeast suspension and the assay was incubated at $35^{\circ} \mathrm{C}$ for $24 \mathrm{~h}$. Ten-microliter $(10 \mu \mathrm{L})$ aliquots were removed with a sterile calibrated loop at predetermined time intervals $(0 \mathrm{~h}, 2 \mathrm{~h}, 4 \mathrm{~h}, 6 \mathrm{~h}$, and $24 \mathrm{~h})$ and uniformly seeded on the surface of SDA culture medium. The assay was incubated at $35^{\circ} \mathrm{C}$ for $24-48 \mathrm{~h}$, and at the elapsed incubation time, the count was done $(\mathrm{CFU} / \mathrm{mL})$. Controls for yeast growth and the antifungal standard were also performed. The experiment was performed in duplicate.

After the incubation period, the number of viable cells was counted and expressed in CFU/mL. The results were analyzed and represented graphically, a microbial death curve as a function of time. Fungicidal activity of the product-test was considered when there was a reduction in microbial growth of $\geq 3 \log _{10}$ in CFU/mL, resulting in about $99.9 \%$ reduction in $\mathrm{CFU} / \mathrm{mL}$ relative to the initial inoculum. Fungistatic activity was considered as reduction in growth lower than $99.9 \%$ or $<3 \log _{10}$ in CFU/mL from the initial inoculum [31].

2.7. Effect of Citral on the Micromorphology of C. albicans. To evaluate possible changes in micromorphology caused by citral and amphotericin B against $C$. albicans ATCC 76485 and LM-70, microculture technique for yeast was employed using agar-cornmeal in a moist chamber/Petri dish, in accordance with Dalmau [32]. Initially, $1 \mathrm{~mL}$ of liquefied cornmeal agar containing the test product was poured onto a slide. After solidification of the medium, an inoculum of recent cultures of the strains was seeded forming two parallel striations on the cornmeal agar and covered with a sterile coverslip. The filter paper was then soaked in sterile distilled water to maintain moisture in the system. This test system was incubated at $35^{\circ} \mathrm{C}$ for $24-48 \mathrm{~h}$. The slides were examined by light microscopy at a magnification of $40 \mathrm{x}$ to observe the formation (or not) of characteristic structures such as blastoconidia, pseudohyphae, and chlamydoconidia, and images were registered. Microculture controls (including the antifungal standard) were also completed [33-35]. The test was performed in duplicate.

2.8. Sorbitol Assay-Effect of Citral on the Cell Wall of C. albicans. The assay was performed using medium with and without sorbitol (control) to evaluate possible mechanisms involved in the antifungal activity of the test product on the yeast cell wall. The sorbitol was added to the culture medium in a final concentration of $0.8 \mathrm{M}$. The assay was performed by microdilution method in 96-well plates in a "U" (Alamar, Diadema, SP, Brazil). The plates were sealed aseptically, incubated at $35^{\circ} \mathrm{C}$, and readings were taken at 2 and 7 days. Based on the ability of sorbitol to act as a fungal cell wall osmotic protective agent, the higher MIC values observed in the medium with added sorbitol compared to the standard medium implicated the cell wall as one of the possible cell targets for the product tested [36]. Amphotericin $\mathrm{B}$ was used as the control drug. The assay was performed in duplicate and expressed as the geometric mean of the results.

\subsection{Ergosterol Binding Assay-MIC Value Determination in} Presence of Ergosterol. To assess if the product binds to the fungal membrane sterols, this experiment was performed according to the method described by Escalante et al. [37], with some modifications. The ergosterol was prepared at the time of test execution, where it was first pulverized (with the help of a pre-sterilized porcelain mortar and pestle) and dissolved in DMSO (no more than $10 \%$ of final volume), and Tween 80 at 1\%, in accordance with the desired concentration and volume. The formed emulsion was then homogenized, heated to augment the solubility, and diluted with the liquid culture medium.

The MIC of citral against C. albicans was determined by using broth microdilution techniques according to the guidelines of the CLSI for yeasts (M27-A2) [27], in the presence and absence of exogenous ergosterol (Sigma-Aldrich, São Paulo, SP, Brazil) added to the assay medium, in different lines of the same microplate. Briefly, a solution of citral was doubly diluted serially with RPMI-1640 (volume $=100 \mu \mathrm{L}$ ) containing plus ergosterol at a concentration of $400 \mu \mathrm{g} / \mathrm{mL}$. A volume of $10 \mu \mathrm{L}$ of yeast suspension (0,5 McFarland) was added to each well. Finally, we realized the same procedure for amphotericin B, whose interaction with membrane ergosterol is already known, which served as a control drug. The plates were sealed and incubated at $35^{\circ} \mathrm{C}$. The plates were read after $24 \mathrm{~h}$ of incubation and MIC was determined as the lowest concentration of test agent inhibiting the visible growth. This assay was carried out in duplicate and the geometric mean values were calculated. Thus, this binding assay reflected the ability of compound to bind with the ergosterol.

\section{Results and Discussion}

The results for citral's antifungal activity against $C$. albicans strains were determined using the MIC and MFC in broth microdilutions. The MIC of citral was $64 \mu \mathrm{g} / \mathrm{mL}$, inhibiting the growth of all tested fungal strains. Amphotericin B retained a lesser MIC than the phytoconstituent at $2 \mu \mathrm{g} / \mathrm{mL}$ MIC. The results for the control (Tween 80) showed no fungal growth inhibition; fungal growth in the medium without added drug was detected (sterile control).

The MFC against these microorganisms almost entirely coincided with the MIC $(64 \mu \mathrm{g} / \mathrm{mL})$, except that for the LM-11 strain it was $256 \mu \mathrm{g} / \mathrm{mL}$. However, the MFC of amphotericin B ranged from 2 to $4 \mu \mathrm{g} / \mathrm{mL}$, eight strains (with MFC equal to the MIC), and two strains with 2 times the MIC value $(4 \mu \mathrm{g} / \mathrm{mL})$.

In accordance with the above results, the strains ATCC 76485 and LM-70 were selected for further testing. The MIC for citral and for amphotericin B both strains was 64 and $2 \mu \mathrm{g} / \mathrm{mL}$, respectively. 
The antimicrobial activity of citral has been confirmed in vitro against Saccharomyces cerevisiae [13] and also in fruit salad [15]. This has been attributed to its high concentrations of citral, whose antimicrobial potential is known, and reported by other authors $[10,12,16,20,38]$. More recently, studies have shown that citral can also be used as an antiprotozoal drug. Cardoso and Soares [39] have shown that citral effectively blocked the differentiation from epimastigote to trypomastigote (metacyclogenesis) of Trypanosoma cruzi in vitro. Citral may be a good candidate drug for new inhibition studies to analyze the process of metacyclogenesis for T. cruzi [39].

It has been reported that citral (at 25-200 $\mu \mathrm{g} / \mathrm{mL}$ ) and lemongrass oil, Cymbopogon citratus (at $100 \mu \mathrm{g} / \mathrm{mL}$ ), have antifungal activity, inhibiting the mycelial growth of $C$. albicans, which suggests the potential value of this oil to treat oral or vaginal candidiasis. The lemongrass oil is characterized by monoterpene compounds, and citral is the principal component present at levels of approximately $80 \%$ [40]. Similarly, De billerbeck et al. [41] demonstrated that citral was responsible for $70-80 \%$ of the antifungal activity of Cymbopogon citratus essential oil.

In the present study, citral showed activity against $C$. albicans isolates, confirming the results obtained in previous studies [12, 23, 42-45]. However, citral exhibited excellent activity, even more effective than previously reported, where the compound exhibited antifungal activity in concentrations greater than $256 \mu \mathrm{g} / \mathrm{mL}$ against C. albicans [24, 42-44].

The product was therefore considered actively antifungal in accordance with the parameters defined by Morales et al. [28].

Yeast growth was analyzed over time while subjected to various concentrations of the test product. Two C. albicans strains (ATCC 76485 and LM 70) were subjected to the experimental method for microbial death kinetics (Figure 1). The test realizes a viable cell count, checking whether a drug has fungistatic or fungicidal action, as well as analyzing the microorganism-test product interaction, in order to characterize a dynamic relationship between concentration and activity over time [31].

The graphs show the $\log _{10}$ of $\mathrm{CFU} / \mathrm{mL}$ versus time of exposure in the presence of citral $(\mathrm{MIC} / 2, \mathrm{MIC}$, and $\mathrm{MIC} \times$ 2 ), the standard antifungal, and the control. Analysis of the graph reveals that the citral concentration MIC/2 has fungistatic activity, as there was a reduction smaller than 3 $\log _{10} \mathrm{CFU} / \mathrm{mL}$ of the initial inoculum; this behavior was also seen for the MIC at up to 2 hours of exposure. At 4 hours' exposure time to citral at concentrations of MIC or MIC $\times 2$, we see fungicidal activity (reduction above $3 \log _{10}$ of CFU/mL of initial inoculum). Therefore, it was possible to identify in the death kinetics a transition between fungistatic and fungicidal activity, revealing citral's concentration-dependent fungicidal activity. The results obtained in this study for $C$. albicans in the presence of citral resemble those of Zore et al. [24] also for C. albicans, with regard to the decrease of cell viability in the initial 2 hours. However, the authors noted that 2 hours were required to kill $99.9 \%$ of the inoculum at a concentration of $640 \mu \mathrm{g} / \mathrm{mL}$. In the present study, the time required for presentation of fungicidal activity was 2 hours for
MIC $\times 2$ and 4 hours for MIC. Essential oil rich in citral has shown microbiocidic activity against C. albicans, Escherichia coli, and Staphylococcus aureus, being able to "instantly" kill (10 $\mathrm{min})$ at a concentration of $1 \mathrm{mg} / \mathrm{mL}$, indicating its broad spectrum of antimicrobial activity in easily achievable concentrations [46].

As shown in Figures 1(c) and 1(d), the time-kill assay, a $100 \%$ reduction in $C$. albicans viability was observed with exposure of $24 \mathrm{~h}$ for MIC and of $2 \mathrm{~h}$ for MIC $\times$ 2 with amphotericin $\mathrm{B}$. These results confirm the results obtained by Cantón et al. [47] where the fungicidal activity of amphotericin B against C. albicans was very quick (2 to 4 hours in concentrations equal to $\mathrm{MIC} \times 2$ ), with a decrease in the number of CFU per milliliter that was greater than $3 \log _{10}$ units (99.9\%). The literature has reported that, among the drugs commonly used to treat fungal infections, amphotericin B and nystatin have concentration-dependent fungicidal effect [31].

The micromorphological evaluations of C. albicans ATCC 76485 and LM-70 under an optical microscope (for the control) revealed the presence of structures indicating fungal growth: pseudohyphae, blastoconidia, and chlamydoconidia (Figure 2). In the presence of citral we observed only blastoconidia. Thus, the fungal micromorphological assay indicated that the test product was able to inhibit the formation of pseudohyphae and chlamydoconidia. The same was observed for amphotericin B. A previous study has shown that lemongrass essential oil is rich in citral, and having a concentration of $32.7 \mu \mathrm{g} / \mathrm{mL}$ is highly effective in the vapor phase against C. albicans, causing deleterious morphological changes in cellular structures and cell surface alterations [48, 49].

According to Alves et al. [50], morphological changes are associated with microorganism pathogenicity, and it is believed that local environmental factors affect the physiological status of commensal yeast, making them infectious.

The yeast-hyphae morphological transition is considered highly relevant to the virulence of fungal infections. Several studies have reported associations between morphogenesis and virulence for dimorphic fungi that are human pathogens [51-55]. Thus, change in morphology from the yeast form to the filamentous form plays a vital role in the pathogenesis of fungal infections and suggests that associated factors for this conversion process represent promising therapeutic targets $[3,51]$. There are reports indicating that mutant $C$. albicans strains incapable of hyphal formation are, generally, nonvirulent in mouse models of experimental disseminated or mucosal candidiasis [56-59]. The results for citral in this work may therefore be of great importance towards the development of some future antifungal agent.

To investigate the action of the product on the fungal cell wall we performed an assay with sorbitol (Table 1), which has an osmoprotectant function. Sorbitol is an osmotic protector used to stabilize fungi protoplasts. Specific fungal cell wall inhibitors share a distinctive characteristic where their antifungal effects are reversed in mediums containing sorbitol [36]. Cells protected with sorbitol can grow in the presence of fungal cell wall inhibitors, whereas growth would be inhibited in the absence of sorbitol. This effect is detected 


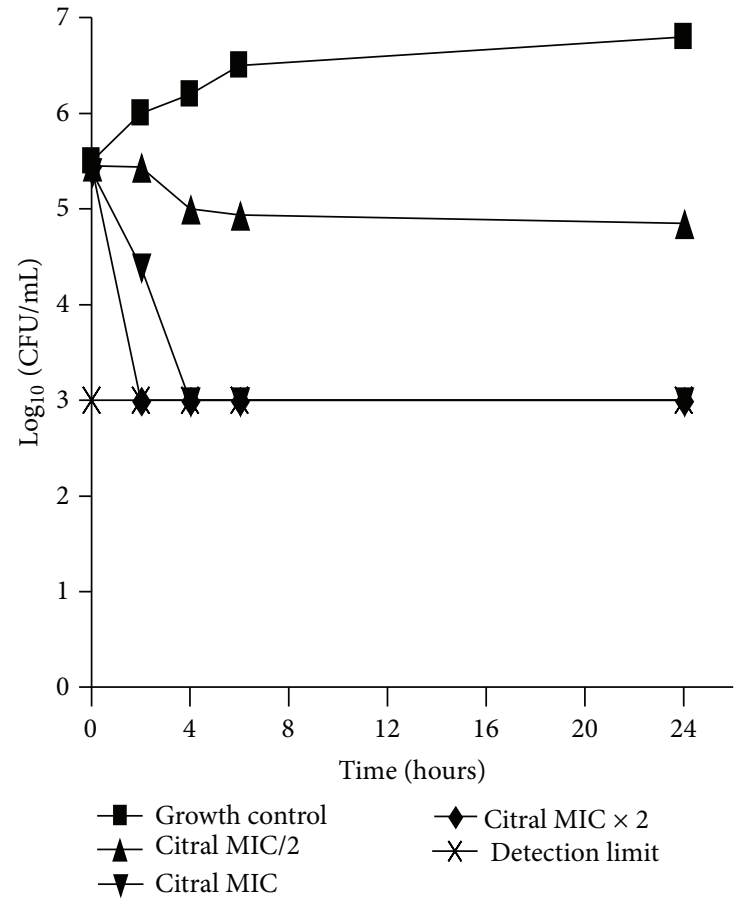

(a)

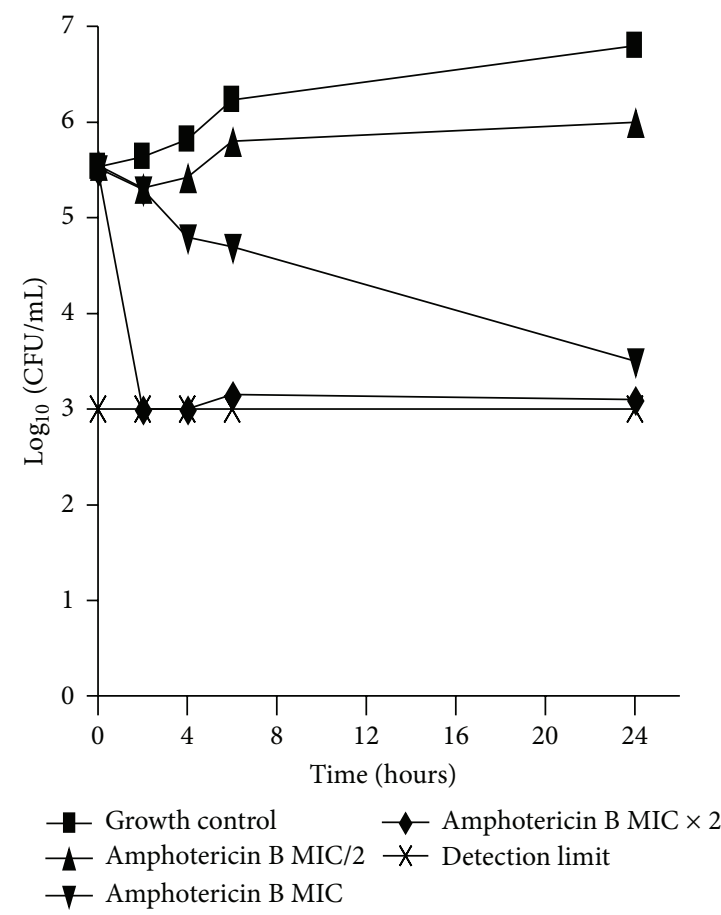

(c)

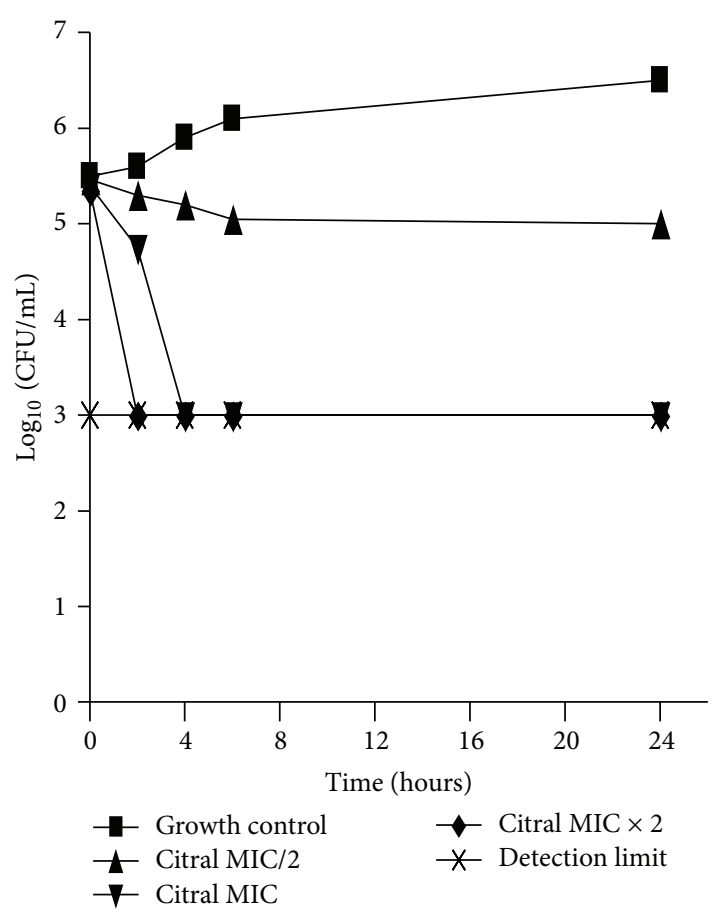

(b)

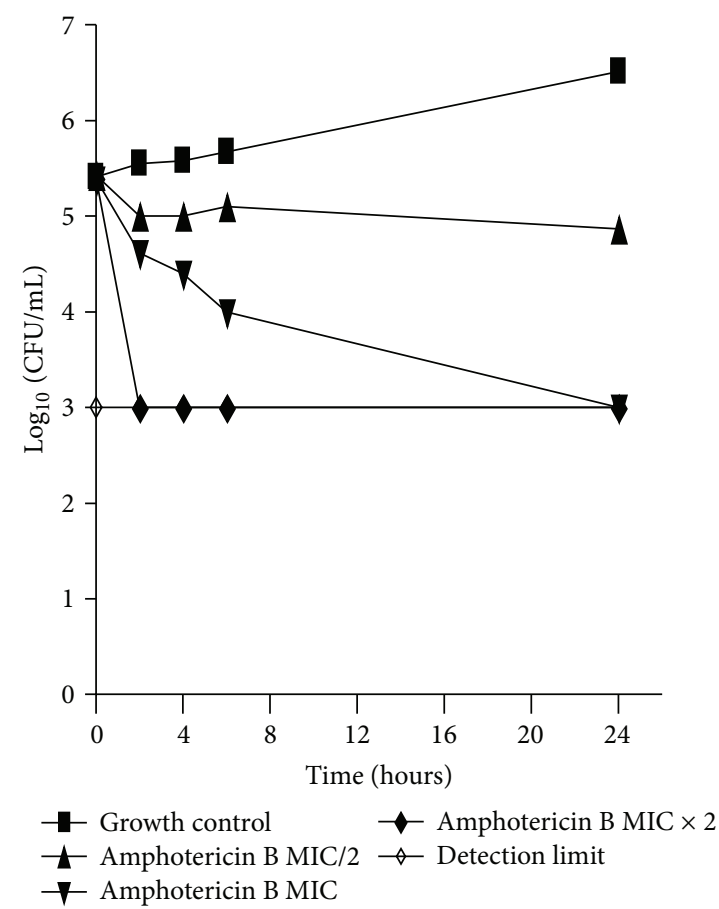

(d)

Figure 1: (a) and (c) Time-death curve for C. albicans ATCC 76485 when exposed to various concentrations of citral and amphotericin B, respectively. (b) and (d) Time-death curve for C. albicans LM-70 when exposed to various concentrations of citral and amphotericin B, respectively.

by increases in the MIC value as observed in medium with sorbitol as compared to the MIC value in medium without sorbitol (standard medium) [36, 60]. Osmotic destabilizing agents and disrupting the cell wall lead to rearrangements of the cell wall and allow the fungal cells to survive [27].
In this paper, the MIC values of citral in both experiments, in mediums with and without sorbitol, were identical, suggesting that citral does not act by inhibiting fungal cell wall synthesis, but probably by affecting another target. These results are in agreement with those reported by Lima et al. 


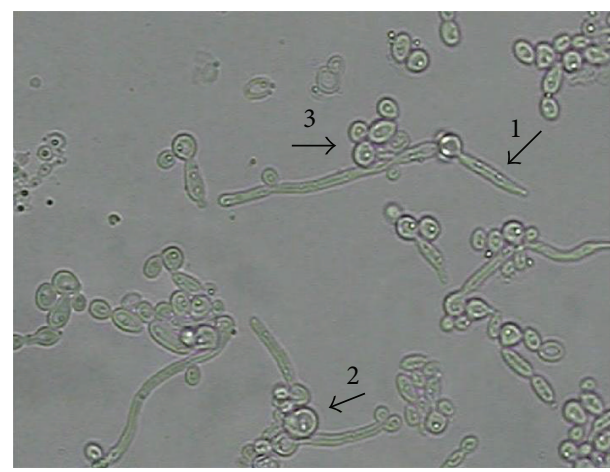

(a)

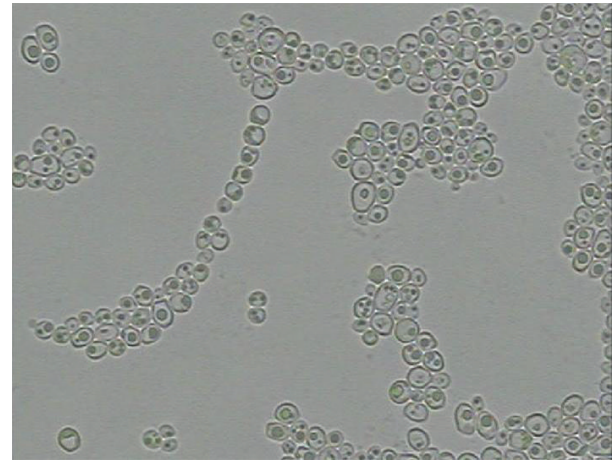

(c)

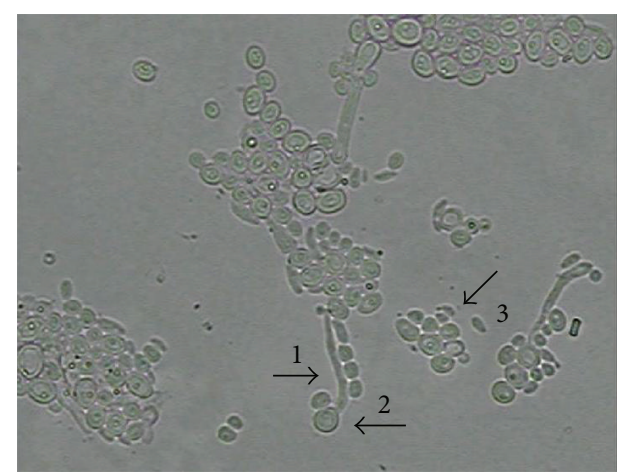

(b)

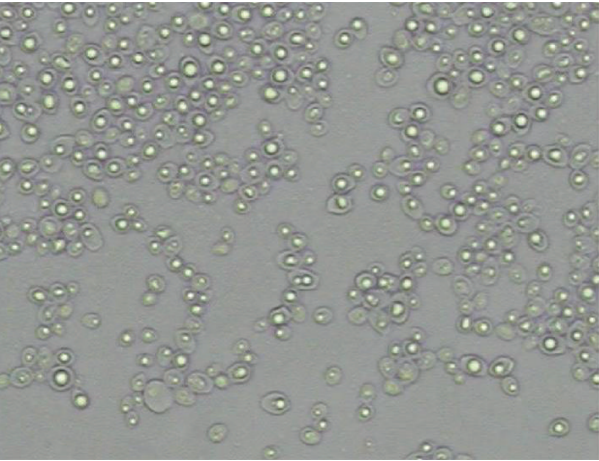

(d)

Figure 2: Micromorphology of Candida albicans strains in the absence (control) and presence of citral and amphotericin B. (a) C. albicans ATCC 76485 and (b) C. albicans LM-70 (in the absence of the product) as controls showing the presence of blastoconidia, chlamydoconidia, and pseudohyphae. (c) Under the action of amphotericin B-MIC. (d) Under the action of citral-MIC $\times 2$. (1) Pseudohyphae; (2) chlamydoconidia; and (3) blastoconidia.

TABLE 1: MIC values $(\mu \mathrm{g} / \mathrm{mL})$ of drugs in the absence and presence of sorbitol $(0.8 \mathrm{M})$ and ergosterol $(400 \mu \mathrm{g} / \mathrm{mL})$ against C. albicans ATCC 76485 and LM-70.

\begin{tabular}{lcccc}
\hline \multirow{2}{*}{ Drugs } & \multicolumn{2}{c}{ Sorbitol } & \multicolumn{2}{c}{ Ergosterol } \\
& Absence & Presence & Absence & Presence \\
\hline Citral & 64 & 64 & 64 & 64 \\
Amphotericin B & - & - & 2 & 128 \\
\hline
\end{tabular}

${ }^{\mathrm{a}}$ Positive control. - : not tested.

[44] who have also described the antifungal activity of this volatile compound against $C$. albicans.

According to Harris [61], citral appears to act predominantly on the fungal cell membrane, affecting its structure, blocking its synthesis, and causing cell death, while inhibiting spore germination, proliferation, and cellular respiration. The literature suggests that the antifungal activity of citral is due to its ability to form a charge transfer complex with fungal cell tryptophan, resulting in the death of the fungi [62].

Considering this possible fungal cell membrane interference of citral, the compound was tested to investigate its ability to form complexes with ergosterol (Table 1).

Ergosterol is the major sterol component present in the plasma membrane of fungi and plays the same role in fungal membranes that cholesterol plays in mammalian cell membranes [63]. Thus, these two sterols seem to exhibit qualitatively similar properties.

If the activity of citral is caused by binding to ergosterol, the exogenous ergosterol would prevent the binding to ergosterol in the fungal membranes. Consequently, MIC increase for citral (in the presence of exogenous ergosterol in relation to the control assay) would occur because only increased product concentration in the growth medium might assure interaction with ergosterol in the fungal membranes [37, 64]. Thus, the effect of exogenous ergosterol on citral and amphotericin B MIC was determined. As can be seen, citral displayed no changes in MIC values; the values were identical in medium with and without additional ergosterol. This indicates that the mechanism of action of citral does not involve complexation with ergosterol. However, amphotericin B does complicate with ergosterol, thus showing an increase in its MIC of 64 times (Table 1). These results are consistent with previous studies for C. albicans, in which, in the presence of ergosterol, the MIC value of amphotericin B increased 32 times; the same was not observed for the MIC of citral [54]. However, the results obtained recently by Rajput and Karuppayil [65] demonstrate that citral used at the CIM value altered the ergosterol profile. Of the molecules tested, citral was one of the most effective at its MIC causing a $99 \%$ reduction in the total ergosterol content. One may attribute the divergent results to the methodological differences, since 
in the cited work the effect on sterol profile was evaluated by sterol quantitation method.

In a recent study Tao et al. [22] showed that citral considerably impaired ergosterol biosynthesis in cells of Penicillium italicum, significantly decreasing lipid levels, suggesting that the plasma membrane may well be an important citral antifungal target.

More recently Zhou et al. [21] evaluated the antifungal activity of three volatile compounds: citral, octanal, and $\alpha$ terpineol against Geotrichum citri-aurantii. It was found that citral in the study was able to significantly inhibit mycelial growth. Antifungal activity was attributed to cell membrane disruption and to consequent loss of cellular components. Another study also showed that citral at a concentration of $200 \mu \mathrm{g} / \mathrm{mL}$ irreversibly damaged cell organelles and the cell membrane of Trichophyton mentagrophytes [66].

It is commonly recognized that the presence of sterols in the fungal membrane is essential for the biological activity of amphotericin B, that is, for the formation of transmembrane ion channels. The selective toxicity of the drug for the fungal cell is ascribed to the fact that it is more potent against fungal cell membranes containing ergosterol than against mammalian membranes with cholesterol [67].

\section{Conclusions}

Based on these results, the present study demonstrated that citral has significant antifungal activity against C. albicans and revealed that the product concentrations inhibiting growth are the same as those causing death. We highlight that the death kinetics of this compound rise quickly and with increased drug concentrations. Another important aspect was that citral was able to alter the morphology of this species, and the probable mechanism of action does not involve either the cell wall or ergosterol. Therefore, the test product is presented as a relevant and promising antifungal which can be considered as an alternative prototype for production of a new and future antifungal, and thus contributing to the existing arsenal of products with proven antifungal activity against C. albicans. Investigations of this nature are important since they provide clearer expectations for future pharmacological studies, with the view of better understanding of citral's mode of action, its toxicity, and its possible therapeutic application.

\section{Conflict of Interests}

The authors declare that there is no conflict of interests regarding the publication of this paper.

\section{Authors' Contribution}

The authors Maria Clerya Alvino Leite, André Parente de Brito Bezerra, Janiere Pereira de Sousa, Felipe Queiroga Sarmento Guerra, and Edeltrudes de Oliveira Lima are responsible for drafting the paper and listed below are the individual contributions of each author to the paper. Maria Clerya Alvino Leite participated in the project design, collection and analysis of data, drafting the paper, and critical revision of the intellectual content. André Parente de Brito Bezerra participated in data collection, data analysis, and revision of the paper. Janiere Pereira de Sousa participated in data collection, data analysis, and revision of the paper. Felipe Queiroga Sarmento Guerra participated in data collection, data analysis, and revision of the paper. Edeltrudes de Oliveira Lima guided all stages of the work and participated in both review and drafting of the project and the paper, including final approval of the version to be published.

\section{Acknowledgments}

The authors are grateful to the Federal University of Paraíba (UFPB) and to David Harding who edited the English version of the paper.

\section{References}

[1] S. Biswas, P. van Dijck, and A. Datta, "Environmental sensing and signal transduction pathways regulating morphopathogenic determinants of Candida albicans," Microbiology and Molecular Biology Reviews, vol. 71, no. 2, pp. 348-376, 2007.

[2] H. Zhang, H. Chen, J. Niu, Y. Wang, and L. Xie, "Role of adaptive immunity in the pathogenesis of Candida albicans keratitis," Investigative Ophthalmology and Visual Science, vol. 50, no. 6, pp. 2653-2659, 2009.

[3] R. A. Monge, E. Román, C. Nombela, and J. Pla, "The MAP kinase signal transduction network in Candida albicans," Microbiology, vol. 152, no. 4, pp. 905-912, 2006.

[4] M. Richardson and C. Lass-Flörl, "Changing epidemiology of systemic fungal infections," Clinical Microbiology and Infection, vol. 14 , no. 4, pp. 5-24, 2008.

[5] F. Bakkali, S. Averbeck, D. Averbeck, and M. Idaomar, "Biological effects of essential oils-a review," Food and Chemical Toxicology, vol. 46, no. 2, pp. 446-475, 2008.

[6] M. Friedman, P. R. Henika, C. E. Levin, and R. E. Mandrell, "Antibacterial activities of plant essential oils and their components against Escherichia coli O157:H7 and Salmonella enterica in apple juice," Journal of Agricultural and Food Chemistry, vol. 52, no. 19, pp. 6042-6048, 2004.

[7] E. Lewinsohn, N. Dudai, Y. Tadmor et al., "Histochemical localization of citral accumulation in lemongrass leaves (Cymbopogon citratus (DC.) Stapf., Poaceae)," Annals of Botany, vol. 81, no. 1, pp. 35-39, 1998.

[8] V. Rodov, S. Ben-Yehoshua, F. de Qiu, J. J. Kim, and R. Ashkenazi, "Preformed antifungal compounds of lemon fruit: citral and its relation to disease resistance," Journal of Agricultural and Food Chemistry, vol. 43, no. 4, pp. 1057-1061, 1995.

[9] N. G. Tzortzakis and C. D. Economakis, "Antifungal activity of lemongrass (Cympopogon citratus L.) essential oil against key postharvest pathogens," Innovative Food Science and Emerging Technologies, vol. 8, no. 2, pp. 253-258, 2007.

[10] E. Wuryatmo, A. Klieber, and E. S. Scott, "Inhibition of citrus postharvest pathogens by vapor of citral and related compounds in culture," Journal of Agricultural and Food Chemistry, vol. 51, no. 9, pp. 2637-2640, 2003.

[11] F. A. Dawson, “The amazing terpenes," Naval Stores Review, vol. 104, pp. 6-12, 1994. 
[12] A. M. Marques, C. H. P. Lima, D. S. Alviano, C. S. Alviano, R. L. Esteves, and M. A. C. Kaplan, "Traditional use, chemical composition and antimicrobial activity of Pectis brevipedunculata essential oil: a correlated lemongrass species in Brazil," Emirates Journal of Food and Agriculture, vol. 25, pp. 798-808, 2013.

[13] N. Belletti, M. Ndagijimana, C. Sisto, M. E. Guerzoni, R. Lanciotti, and F. Gardini, "Evaluation of the antimicrobial activity of citrus essences on Saccharomyces cerevisiae," Journal of Agricultural and Food Chemistry, vol. 52, pp. 6932-6938, 2004.

[14] N. Belletti, S. S. Kamdem, F. Patrignani, R. Lanciotti, A. Covelli, and F. Gardini, "Antimicrobial activity of aroma compounds against Saccharomyces cerevisiae and improvement of microbiological stability of soft drinks as assessed by logistic regression," Applied and Environmental Microbiology, vol. 73, no. 17, pp. 5580-5586, 2007.

[15] N. Belletti, R. Lanciotti, F. Patrignani, and F. Gardini, "Antimicrobial efficacy of citron essential oil on spoilage and pathogenic microorganisms in fruit-based salads," Journal of Food Science, vol. 73, no. 7, pp. M331-M338, 2008.

[16] N. Belletti, S. S. Kamdem, G. Tabanelli, R. Lanciotti, and F. Gardini, "Modeling of combined effects of citral, linalool and $\beta$-pinene used against Saccharomyces cerevisiae in citrus-based beverages subjected to a mild heat treatment," International Journal of Food Microbiology, vol. 136, no. 3, pp. 283-289, 2010.

[17] S. Ben-Yehoshua, V. Rodov, J. J. Kim, and S. Carmeli, "Preformed and induced antifungal materials of citrus fruits in relation to the enhancement of decay resistance by heat and ultraviolet treatments," Journal of Agricultural and Food Chemistry, vol. 40, no. 7, pp. 1217-1221, 1992.

[18] D. R. L. Caccioni, M. Guizzardi, D. M. Biondi, A. Renda, and G. Ruberto, "Relationship between volatile components of citrus fruit essential oils and antimicrobial action on Penicillium digitatum and Penicillium italicum," International Journal of Food Microbiology, vol. 43, no. 1-2, pp. 73-79, 1998.

[19] S. Droby, A. Eick, D. Macarisin et al., "Role of citrus volatiles in host recognition, germination and growth of Penicillium digitatum and Penicillium italicum," Postharvest Biology and Technology, vol. 49, no. 3, pp. 386-396, 2008.

[20] K. Rivera-Carriles, A. Argaiz, E. Palou, and A. López-Malo, "Synergistic inhibitory effect of citral with selected phenolics against Zygosaccharomyces bailii," Journal of Food Protection, vol. 68, pp. 602-606, 2005.

[21] H. Zhou, N. Tao, and L. Jia, "Antifungal activity of citral, octanal and $\alpha$-terpineol against Geotrichum citri-aurantii," Food Control, vol. 37, pp. 277-283, 2014.

[22] N. Tao, Q. OuYang, and L. Jia, "Citral inhibits mycelial growth of Penicillium italicum by a membrane damage mechanism," Food Control, vol. 41, pp. 116-121, 2014.

[23] C. D. B. da Silva, S. S. Guterres, V. Weisheimer, and E. E. S. Schapoval, "Antifungal activity of the lemongrass oil and citral against Candida spp," Brazilian Journal of Infectious Diseases, vol. 12, no. 1, pp. 63-66, 2008.

[24] G. B. Zore, A. D. Thakre, S. Jadhav, and S. M. Karuppayil, "Terpenoids inhibit Candida albicans growth by affecting membrane integrity and arrest of cell cycle," Phytomedicine, vol. 18, no. 13, pp. 1181-1190, 2011.

[25] R. Cleeland and E. Squires, "Evalution of new antimicrobials in vitro and in experimental animal infections," in Antibiotics in Laboratory Medicine, V. Lorian, Ed., pp. 739-786, Lippincott Williams \& Wilkins, Baltimore, Md, USA, 3rd edition, 1991.
[26] F. Hadacek and H. Greger, "Testing of antifungal natural products: methodologies, comparability of results and assay choice," Phytochemical Analysis, vol. 11, pp. 137-147, 2000.

[27] Clinical and Laboratory Standards Institute, Reference Method for Broth Dilution Antifungal Susceptibility Testing of Yeasts, CLSI Document M27-A2, CLSI, Philadelphia, Pa, USA, 2nd edition, 2002.

[28] G. Morales, A. Paredes, P. Sierra, and L. A. Loyola, "Antimicrobial activity of three baccharis species used in the traditional medicine of Northern Chile," Molecules, vol. 13, no. 4, pp. 790794, 2008.

[29] M. E. Ernst, M. E. Klepser, E. J. Wolfe, and M. A. Pfaller, "Antifungal dynamics of LY 303366, an investigational echinocandin B analog, against Candida ssp.," Diagnostic Microbiology and Infectious Disease, vol. 26, no. 3-4, pp. 125-131, 1996.

[30] A. Espinel-Ingroff, V. Chaturvedi, A. Fothergill, and M. G. Rinaldi, "Optimal testing conditions for determining MICs and minimum fungicidal concentrations of new and established antifungal agents for uncommon molds: NCCLS collaborative study," Journal of Clinical Microbiology, vol. 40, no. 10, pp. 37763781, 2002.

[31] M. E. Klepser, E. J. Wolfe, R. N. Jones, C. H. Nightingale, and M. A. Pfaller, "Antifungal pharmacodynamic characteristics of fluconazole and amphotericin B tested against Candida albicans," Antimicrobial Agents and Chemotherapy, vol. 41, no. 6, pp. 1392-1395, 1997.

[32] L. M. Dalmau, "Observation on mycological technique with particular references to pathogenic fungi," The Puerto Rico Journal of Public Health and Tropical Medicine, vol. 5, pp. 302311, 1929.

[33] S. Gunji, K. Arima, and T. Beppu, "Screening of antifungal antibiotics according to activities inducing morphological abnormalities,' Agricultural and Biological Chemistry, vol. 47, no. 9, pp. 2061-2069, 1983.

[34] C. P. Kurtzman and J. W. Fell, The Yeats-A Taxonomie Study, Elsevier Science, Amsterdam, The Netherlands, 4th edition, 1998.

[35] E. P. Milan and L. L. Zaror, "Identificação laboratorial," in Micologia médica à luz de autores contemporâneos, J. J. C. Sidrim and M. F. G. Rocha, Eds., pp. 89-101, Guanabara Koogan, Rio de Janeiro, Brazil, 2012.

[36] D. J. Frost, K. D. Brandt, D. Cugier, and R. Goldman, "A whole-cell Candida albicans assay for the detection of inhibitors towards fungal cell wall synthesis and assembly," Journal of Antibiotics, vol. 48, no. 4, pp. 306-310, 1995.

[37] A. Escalante, M. Gattuso, P. Pérez, and S. Zacchino, "Evidence for the mechanism of action of the antifungal phytolaccoside B isolated from Phytolacca tetramera Hauman," Journal of Natural Products, vol. 71, no. 10, pp. 1720-1725, 2008.

[38] G. O. Onawunmi, W. A. Yisak, and E. O. Ogunlana, "Antibacterial constituents in the essential oil of Cymbopogon citratus (DC.) Stapf," Journal of Ethnopharmacology, vol. 12, no. 3, pp. 279-286, 1984.

[39] J. Cardoso and M. J. Soares, "In vitro effects of citral on Trypanosoma cruzi metacyclogenesis," Memorias do Instituto Oswaldo Cruz, vol. 105, no. 8, pp. 1026-1032, 2010.

[40] S. Abe, Y. Sato, S. Inoue et al., "Anti-Candida albicans activity of essential oils including lemongrass (Cymbopogon citratus) oil and its component, citral," Japanese Journal of Medical Mycology, vol. 44, pp. 285-291, 2003.

[41] V. G. De Billerbeck, C. G. Roques, J.-. Bessière, J.-. Fonvieille, and R. Dargent, "Effects of Cymbopogon nardus (L.) W. Watson 
essential oil on the growth and morphogenesis of Aspergillus niger," Canadian Journal of Microbiology, vol. 47, no. 1, pp. 9-17, 2001.

[42] G. O. Onawunmi, "Evaluation of the antimicrobial activity of citral," Letters in Applied Microbiology, vol. 9, no. 3, pp. 105-108, 1989.

[43] I. O. Lima, R. de Araújo G. Oliveira, E. de O. Lima, E. L. de Souza, N. P. Farias, and D. de Fátima Navarro, "Inhibitory effect of some phytochemicals in the growth of yeasts potentially causing opportunistic infections," Brazilian Journal of Pharmaceutical Sciences, vol. 41, no. 2, pp. 199-203, 2005.

[44] I. O. Lima, F. De Medeiros Nóbrega, W. A. De Oliveira et al., "Anti-Candida albicans effectiveness of citral and investigation of mode of action," Pharmaceutical Biology, vol. 50, no. 12, pp. 1536-1541, 2012.

[45] D. R. Oliveira, G. G. Leitão, S. S. Santos et al., "Ethnopharmacological study of two Lippia species from Oriximiná, Brazil," Journal of Ethnopharmacology, vol. 108, pp. 103-108, 2006.

[46] B. R. Singh, V. Singh, R. K. Singh, and N. Ebibeni, "Antimicrobial activity of lemongrass (Cymbopogon citratus) oil against microbes of environmental, clinical and food origin," International Research Journal of Pharmacy and Pharmacology, vol. 1, pp. 228-236, 2011.

[47] E. Cantón, J. Pemán, M. Gobernado, A. Viudes, and A. EspinelIngroff, "Patterns of amphotericin B killing kinetics against seven Candida species," Antimicrobial Agents and Chemotherapy, vol. 48, pp. 2477-2482, 2004.

[48] A. K. Tyagi and A. Malik, "In situ SEM, TEM and AFM studies of the antimicrobial activity of lemon grass oil in liquid and vapour phase against Candida albicans," Micron, vol. 41, no. 7, pp. 797-805, 2010.

[49] A. K. Tyagi and A. Malik, "Liquid and vapour-phase antifungal activities of selected essential oils against Candida albicans: microscopic observations and chemical characterization of Cymbopogon citratus," BMC Complementary and Alternative Medicine, vol. 10, article 65, 2010.

[50] L. A. Alves, I. A. Freires, T. M. Pereira, A. Souza, E. O. Lima, and R. D. Castro, "Effect of Schinus terebinthifolius on Candida albicans growth kinetics, cell wall formation and micromorphology," Acta Odontologica Scandinavica, vol. 71, pp. 965-971, 2013.

[51] P. J. Rooney and B. S. Klein, "Linking fungal morphogenesis with virulence," Cellular Microbiology, vol. 4, no. 3, pp. 127-137, 2002.

[52] N. A. R. Gow, A. J. P. Brown, and F. C. Odds, "Fungal morphogenesis and host invasion," Current Opinion in Microbiology, vol. 5, no. 4, pp. 366-371, 2002.

[53] L. Romani, F. Bistoni, and P. Puccetti, "Adaptation of Candida albicans to the host environment: the role of morphogenesis in virulence and survival in mammalian hosts," Current Opinion in Microbiology, vol. 6, no. 4, pp. 338-343, 2003.

[54] B. S. Klein and B. Tebbets, "Dimorphism and virulence in fungi," Current Opinion in Microbiology, vol. 10, no. 4, pp. 314-319, 2007.

[55] B. Zhai, P. Zhu, D. Foyle, S. Upadhyay, A. Idnurm, and X. Lin, "Congenic strains of the filamentous form of Cryptococcus neoformans for studies of fungal morphogenesis and virulence," Infection and Immunity, vol. 81, no. 7, pp. 2626-2637, 2013.

[56] H. J. Lo, J. R. Köhler, B. DiDomenico, D. Loebenberg, A. Cacciapuoti, and G. R. Fink, "Nonfilamentous C. albicans mutants are avirulent," Cell, vol. 90, no. 5, pp. 939-949, 1997.
[57] C. R. C. Rocha, K. Schröppel, D. Harcus et al., "Signaling through adenylyl cyclase is essential for hyphal growth and virulence in the pathogenic fungus Candida albicans," Molecular Biology of the Cell, vol. 12, no. 11, pp. 3631-3643, 2001.

[58] D. Li, J. Bernhardt, and R. Calderone, "Temporal expression of the Candida albicans genes CHK1 and CSSK1, adherence, and morphogenesis in a model of reconstituted human esophageal epithelial candidiasis," Infection and Immunity, vol. 70, no. 3, pp. 1558-1565, 2002.

[59] A. Marcil, D. Harcus, D. Y. Thomas, and M. Whiteway, “Candida albicans killing by RAW 264.7 mouse macrophage cells: effects of Candida genotype, infection ratios, and gamma interferon treatment," Infection and Immunity, vol. 70, no. 11, pp. 63196329, 2002.

[60] L. Svetaz, M. B. Agüero, S. Alvarez et al., "Antifungal activity of Zuccagnia punctata Cav.: evidence for the mechanism of action," Planta Medica, vol. 73, no. 10, pp. 1074-1080, 2007.

[61] R. Harris, "Progress with superficial mycoses using essential oils," International Journal of Aromatherapy, vol. 12, no. 2, pp. 83-91, 2002.

[62] N. Kurita, M. Miyaji, R. Kurane, and Y. Takahara, "Antifungal activity of components of essential oils," Agricultural and Biological Chemistry, vol. 45, no. 4, pp. 945-952, 1981.

[63] S. M. Bowman and S. J. Free, "The structure and synthesis of the fungal cell wall," BioEssays, vol. 28, no. 8, pp. 799-808, 2006.

[64] C. S. Lunde and I. Kubo, "Effect of polygodial on the mitochondrial ATPase of Saccharomyces cerevisiae," Antimicrobial Agents and Chemotherapy, vol. 44, no. 7, pp. 1943-1953, 2000.

[65] S. B. Rajput and S. M. Karuppayil, "Small molecules inhibit growth, viability and ergosterol biosynthesis in Candida albicans," SpringerPlus, vol. 2, article 26, 2013.

[66] M. J. Park, K. S. Gwak, I. Yang et al., "Effect of citral, eugenol, nerolidol and $\alpha$-terpineol on the ultrastructural changes of Trichophyton mentagrophytes," Fitoterapia, vol. 80, no. 5, pp. 290-296, 2009.

[67] A. Neumann, M. Baginski, and J. Czub, "How do sterols determine the antifungal activity of amphotericin B? Free energy of binding between the drug and its membrane targets," Journal of the American Chemical Society, vol. 132, no. 51, pp. 18266-18272, 2010. 


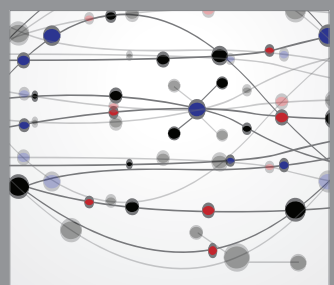

The Scientific World Journal
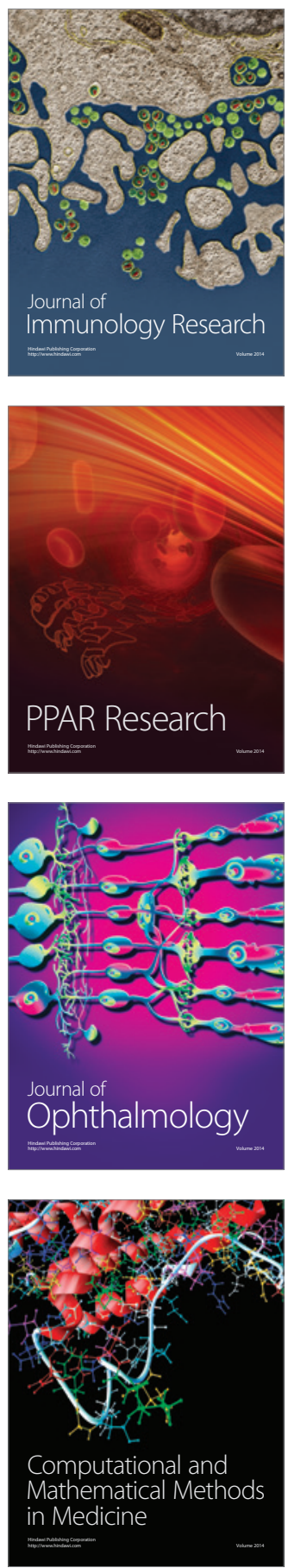

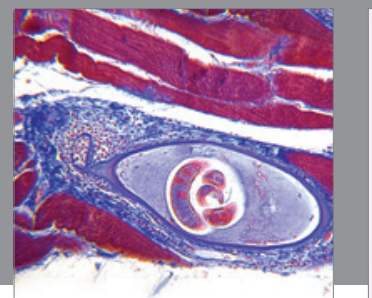

Gastroenterology

Research and Practice
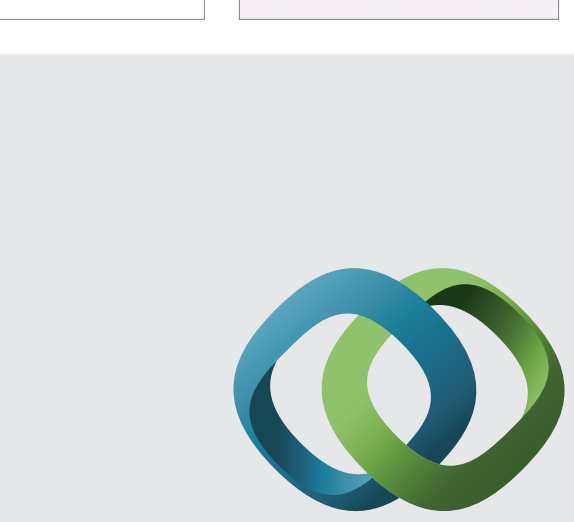

\section{Hindawi}

Submit your manuscripts at

http://www.hindawi.com
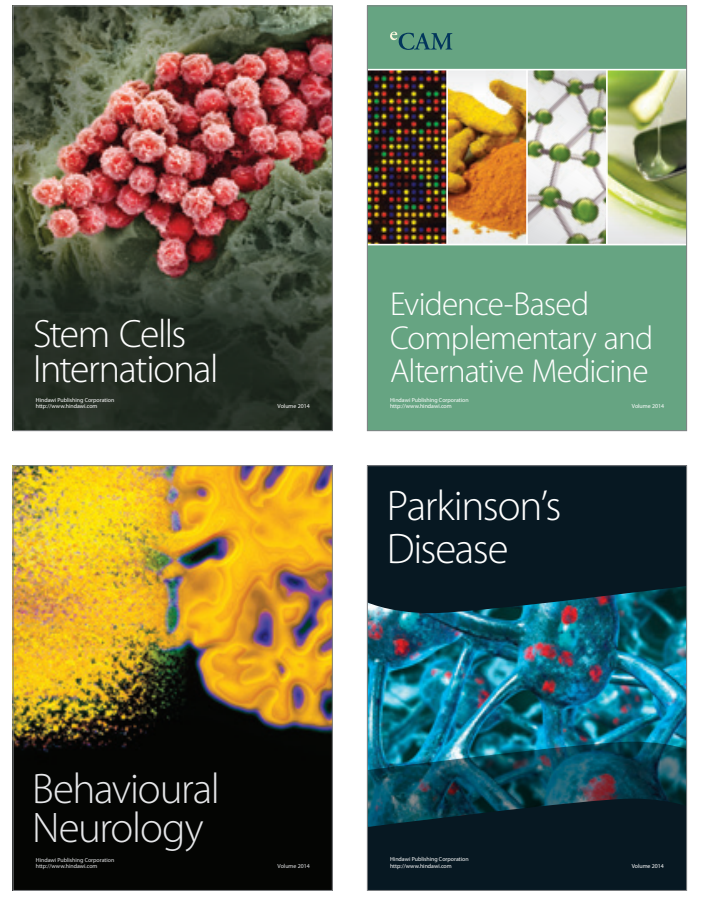
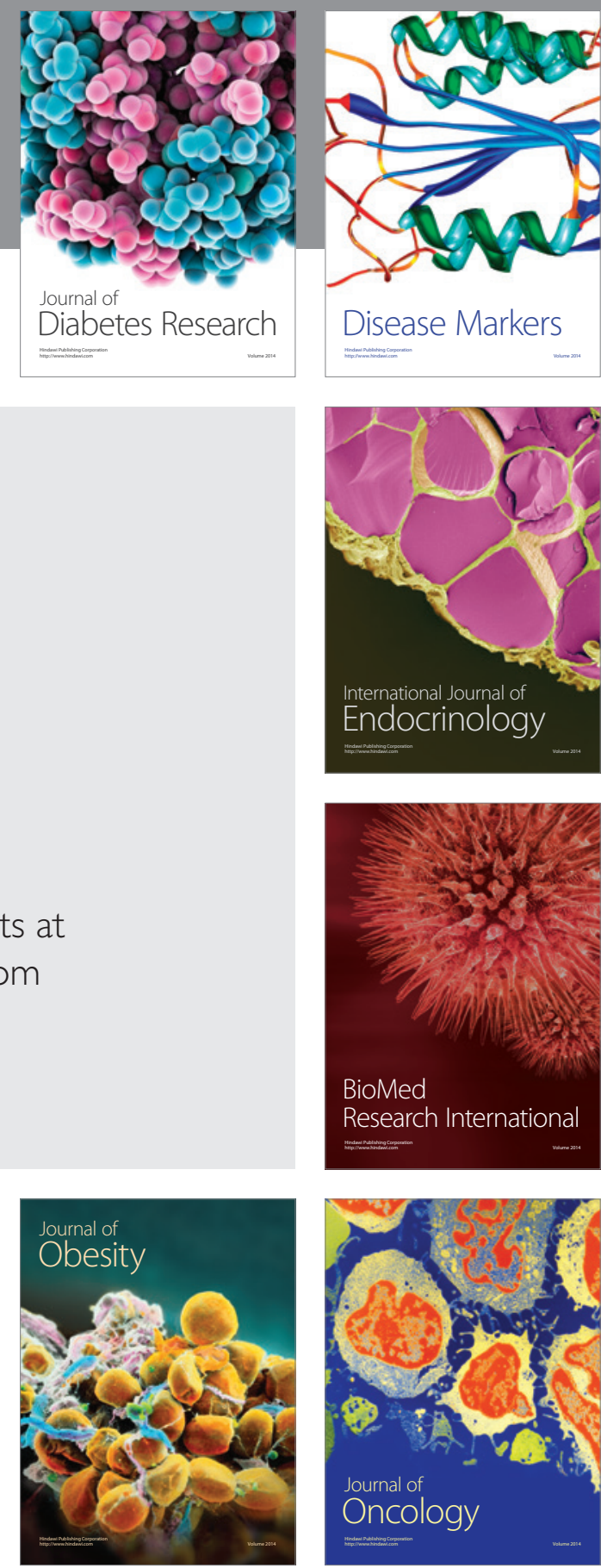

Disease Markers
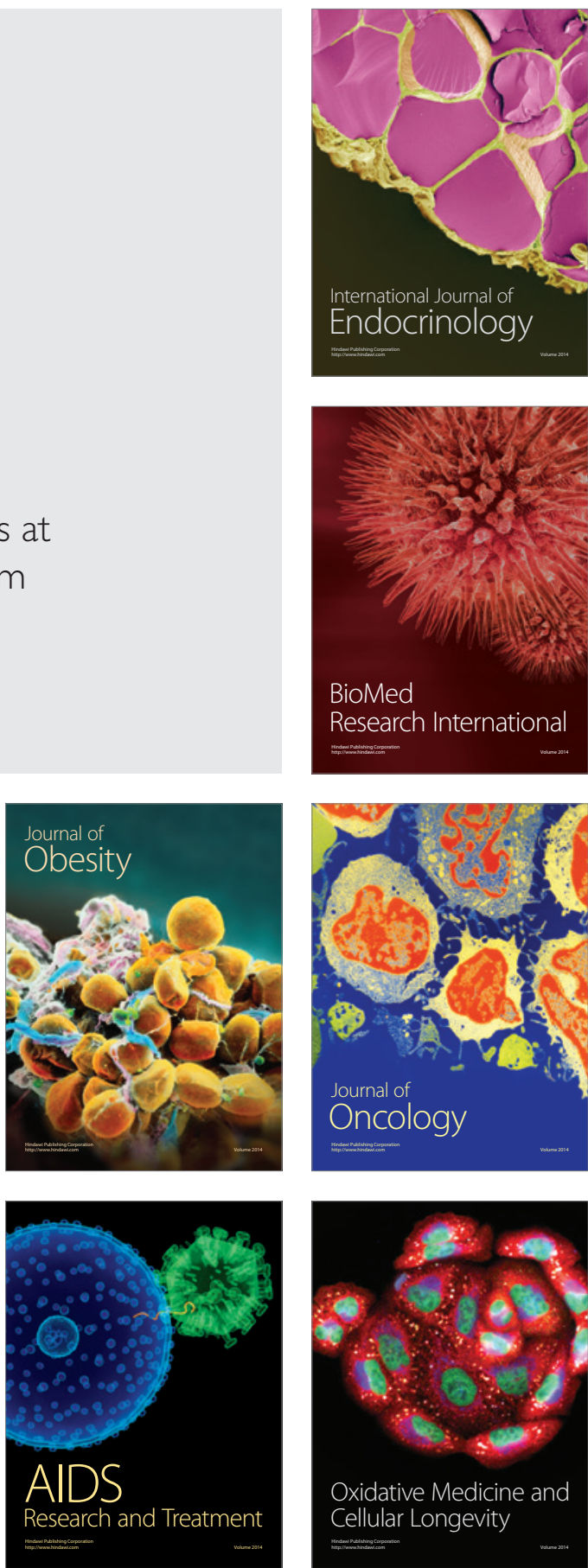